\title{
A Study of Heat Transfer on Front and Back Vented Brake Disc Affecting Vibration
}

\author{
Supachai Lakkam ${ }^{\mathrm{a}, *}$, Phupoom Puangcharoenchai ${ }^{\mathrm{b}}$, and Kullayot Suwantaroj \\ Department of Mechanical Engineering, Faculty of Engineering, Rajamangala University of Technology \\ Phra Nakhon, Bangkok 10800, Thailand \\ E-mail: asupachai.1@rmutp.ac.th (Corresponding author), bphupoom.p@rmutp.ac.th
}

\begin{abstract}
The purpose of this study was to investigate the vibration characteristics of both front and back vented brake discs with physically different shapes. In accordance with theory, the heat transfer rates of the two types of brake disc were different and played an important role in deformation during usage. A dynamometer was used as an engineering tool for the experimental work, with boundary conditions according to the Japanese Automobile Standard JASO C406. One degree of freedom (DOF) acceleration signals on the brake calipers were analysed. Results indicated that the back vented brake disc reduced the vibration by up to $43.5 \%$ compared to the front vented brake disc with braking temperature at $200^{\circ} \mathrm{C}$, initial braking speed $50 \mathrm{~km} / \mathrm{h}$ and hydraulic pressure of $4 \mathrm{MPa}$. Hydraulic pressure at $4 \mathrm{MPa}$ generated the maximum vibration. Initial braking speed and braking temperature were also important factors.
\end{abstract}

Keywords: Heat transfer, front vented brake disc, back vented brake disc, vibration.

ENGINEERING JOURNAL Volume 21 Issue 1

Received 23 March 2016

Accepted 29 June 2016

Published 31 January 2017

Online at http://www.engj.org/

DOI:10.4186/ej.2017.21.1.169 


\section{Introduction}

Automobiles are now a major aspect of Thai life and brake discs are crucial automotive parts for vehicle safety. In recent years, many countries have introduced regulations regarding the design criteria and operational requirements for brake systems implemented on different types of vehicles [1,2]. The variation in brake performance due to the foundation brake system is sensitive and depends on many factors such as brake line pressure and the friction between the brake drum and lining materials [3, 4]. Therefore, foundation brake performance must be ensured before overall brake system performances are addressed $[5,6]$. In the industrial sector, brake discs are either imported or locally produced. There is high local competition regarding the design and efficient development of physical aspects, including the use of local materials in production. Although brake discs are considered as critical safety requirements for vehicles, some Thai manufacturers duplicate parts of the original equipment manufacturers (OEM) or change their designs. These manufacturers do not properly evaluate their products, with a corresponding reduction in production costs. In addition, the absence of a clearly defined procedure for specific safety testing and the high costs of test equipment have resulted in a shortfall of full-size test equipment in the local auto parts industry. This has resulted in reduced quality of auto parts manufactured in Thailand. Therefore, research is required to investigate the efficiency of Thai auto products designed and manufactured from local materials. In the future it is to be hoped that full-size test equipment will be available to design and evaluate brake discs manufactured in Thailand.

The function of a braking system is to retard or reduce speed when a driver desires as vehicle deceleration. The kinetic energy of a vehicle in terms of wheel speed is transduced into heat energy through the application of the braking system. The friction force between the pad and brake disc applies friction torque to the wheel contrary to the car's direction of movement. As a consequence, the vehicle speed is reduced and the heat energy released causes a temperature increase of the brake disc during the brake application. The effect of actual surface area on specific contact temperatures and coefficient of friction determined that maximum temperatures at the contact points did not linearly increase as the contact area ratio decreased [7]. Brake disc and pad material affect the friction generated. Brake discs are mainly made from cast iron class 20, while brake pads are fabricated from compound material consisting of fibre, lubricant, copper and other fillers. These ingredients play an important role in the kinetic friction between the brake disc and pad at the working temperature [8]. The physical action of the brake disc causes heat conduction to the adjacent braking system components. If there is inconsistent dissipation of heat inside the brake disc, then deformation of the brake disc can occur [9]. This problem is normally encountered during operation. Damaged mechanisms and the thermodynamic burden of brake discs were examined for this heat transfer phenomenon [10]. In addition to these problems, friction loss by brake disc deformation can cause brake efficiency to fade [11]. Increased component wear results in a shorter product lifetime [12]. The transition of brake fluid from liquid to vapor due to high temperatures in the brake disc also results in decreased brake efficiency. High temperatures can cause damage and result in cracking of the brake disc material under high thermal stresses. During normal operation a cycle of brake application and subsequent cooling periods is perpetually repeated. Recurring temperature differences also lead to thermal fatigue which can result in the brake disc cracking [13]. Furthermore, these factors also cause vibration [14] and [15]. Accordingly, a brake disc should be able to absorb and dissipate heat effectively throughout repeated cycles of operating conditions. The effects described above are all undesired performance outcomes in a braking system; however, these problems are unavoidable in daily life. Thus, studies of heat collection characteristics of brake discs are necessary to resolve these problems and set design guidelines for suitable disc brakes for each condition. Consequently, heat convection coefficients were examined by finite element analysis to study the temperature diffusion and heat ventilation of both front and back vented brake discs [16]. Moreover, the experimental results revealed that the overall heat convection coefficients of the front vented brake disc were higher than those of the back ones. Therefore, the simulation results determined that the front vented brake disc displayed more efficient heat ventilation than the back, leading to a larger temperature difference between the outboard and inboard rotors which resulted in increased thermal stress. There are many parameters that indicate the degree of vibration. Displacement, acceleration of deformation, loss factors, damping ratio, vibration energy and strain energy are all examples of controlling strategies [17]. Overheated and stressed braking systems are more susceptible to damage during operation.

The vibration was categorised into two directions as in-plane and out-of-plane modes. The difference between them was the mode shapes implicated in the modal coupling mechanism. For a low frequency squeal, the modal coupling resulted from the out-of-plane modes of the rotor and the bending modes of 
the brake pad. For a high frequency squeal, the modal coupling proceeded between the in-plane modes of the rotor. The brake rotor was considerably stiffer in the in-plane direction than in the out-of-plane direction [18]. Figure 1 shows the coupling possibilities between the brake components. Accordingly, the resonance frequencies of the in-plane modes of the brake rotor were higher than those of the out-of-plane (bending) modes. Therefore, the out-of-plane modes were examined.

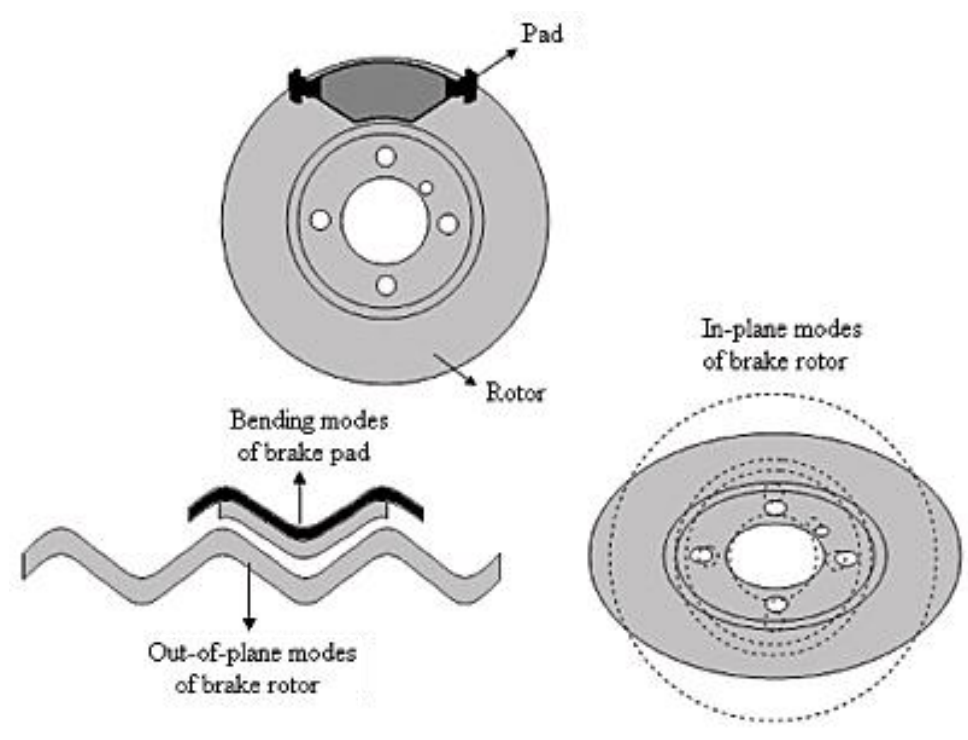

Fig. 1. Coupling possibilities between the brake components [18].

This study, therefore, presented a comprehensive comparison of the vibration characteristics caused by the physical shape of the brake. Special focus was placed on how the initial speed, pressure and temperature of braking affected vibration on both front and back vented brake discs. All experiments were conducted according to brake disc testing standards.

\section{Research Concept and Methodology}

\subsection{Test Bench for Vibration Study on Brake Discs}

To collect the vibration results on the brake discs during rotation, a single dynamometer test bench was proposed as the key engineering tool. Testing methods complied with JASO C406 standard for simulating the working conditions of the brake disc under wind flow. The test bench consisted of four components as shown in Fig. 2:

- Wind Tunnel $(11 \mathrm{~m} / \mathrm{s}$ Wind Speed $)$

- Motor Drive (40 HP)

- Initial Mass $\left(127 \mathrm{~kg} / \mathrm{m}^{2}\right)$

- Disc Specimen (295 mm diameter) 


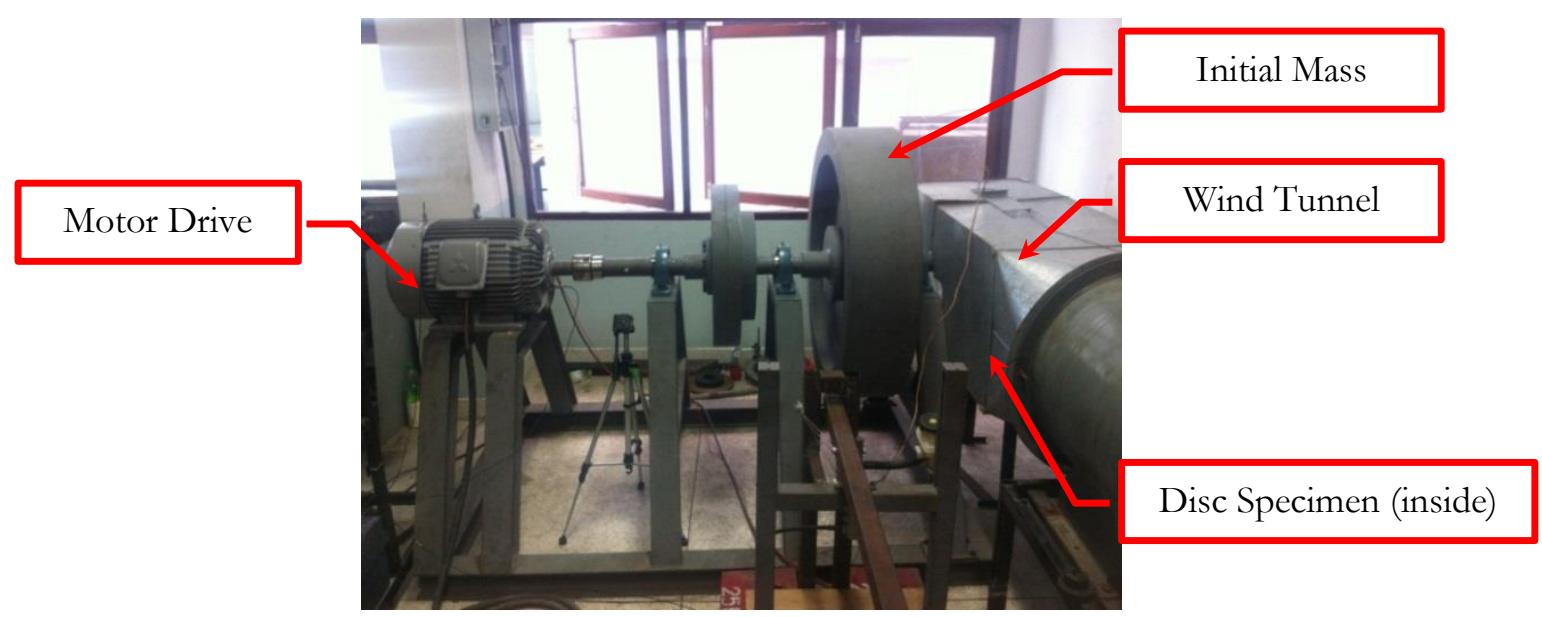

Fig. 2. The single dynamometer test bench.

There were two types of specimen as the front and the back vented brake discs and each had a physically different shape. For maximum heat transfer, the brake discs were designed to reduce bending and improve rotational balance. Both brake discs were tested in the same dimension to ensure good contact surface between the brake pad and brake disc. Testing results are shown in Table 1.

Table 1. Brake disc information.

\begin{tabular}{ccc}
\hline $\begin{array}{c}\text { Type of brake } \\
\text { disc }\end{array}$ & Physical shape & $\begin{array}{c}\text { Two side } \\
\text { contact } \\
\left.\text { surface( } \mathrm{m}^{2}\right)\end{array}$ \\
\hline Front vented & & \\
\hline
\end{tabular}

\subsection{Installation and Testing Conditions}

The theory of heat transfer has three characteristics: heat conduction, heat convection and heat radiation. These three heat transfer procedures are shown in Fig. 3 for the control surface. On a unit area basis, they are conduction from the medium to the control surface ( $q$ " cond), convection from the surface to a fluid $(q$ conv $)$ and net radiation exchange from the surface to the surroundings $(q$ rad $)$. For heat conduction, the heat transfer mechanism for the two types of disc is similar because they have the same material properties. Regarding the surface temperature of the brake disc, the radiation varies depending on the quality of the surface materials [19]. Similarly, the heat radiation rates of both brake discs vary with boundary conditions. Therefore, they are not important factors and can be ignored in terms of this research. The energy balance equation can be expressed as follows (1). 


$$
q_{\text {cond }}^{\prime \prime}-q_{\text {conv }}-q_{\text {rad }}^{\prime}=0
$$

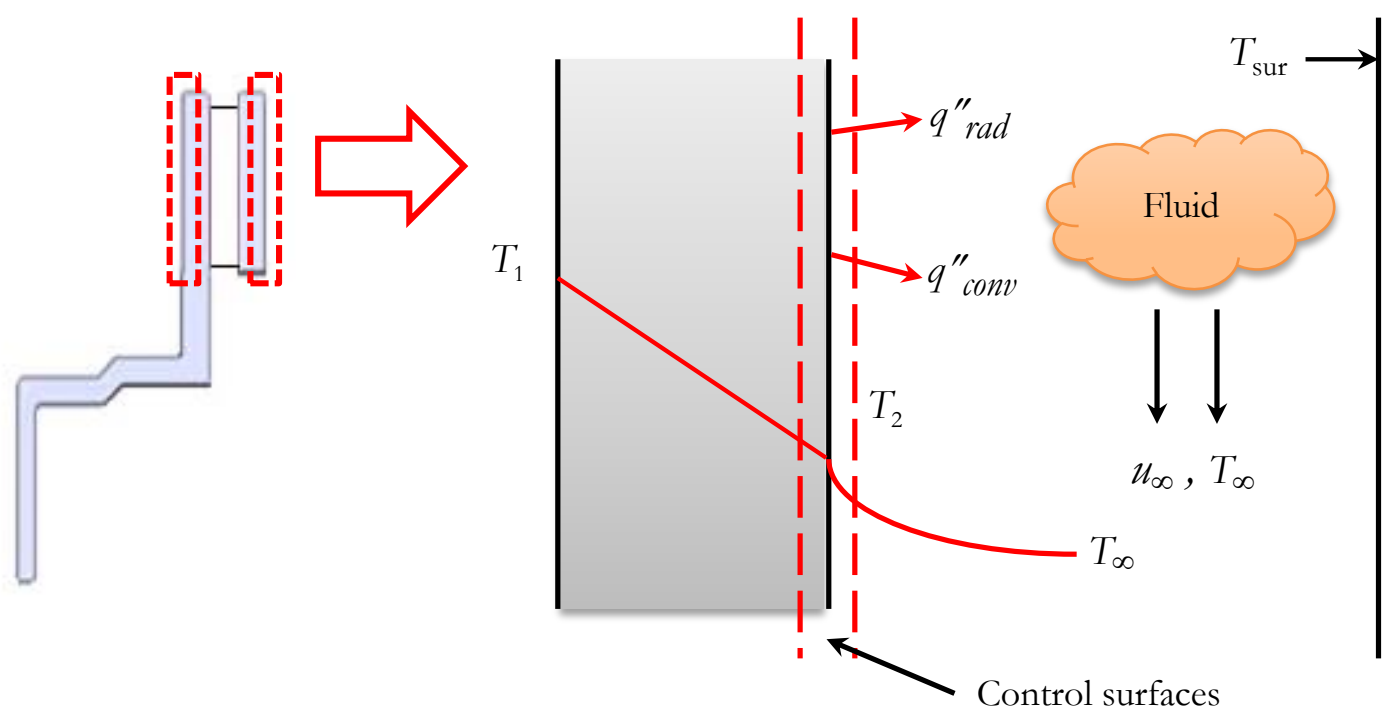

Fig. 3. The energy balance for conversation of energy at the surface of a medium.

Heat convection coefficients of both types of brake disc are shown in Fig. 4 [16]. The heat source temperature of the brake discs was investigated to ensure that it was the same condition. Both types of vented brake disc (front and back) were installed on the single dynamometer. Each specimen was burnished by releasing the lump mass and their temperatures increased to the targets at 100,200 and $300^{\circ} \mathrm{C}$. Braking tests at 2, 4 and $6 \mathrm{MPa}$ were then applied as shown in Fig. 5. For this research, test speeds were selected at 50 and $80 \mathrm{~km} / \mathrm{h}$ as shown in Table 2.

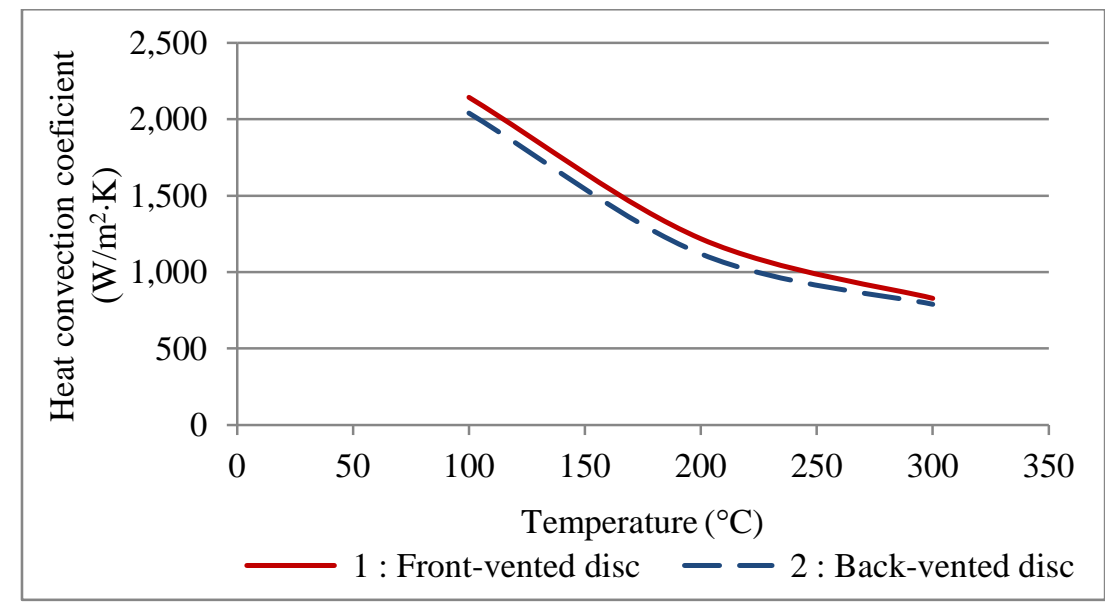

Fig. 4. Heat convection coefficient of both types of brake disc [16]. 


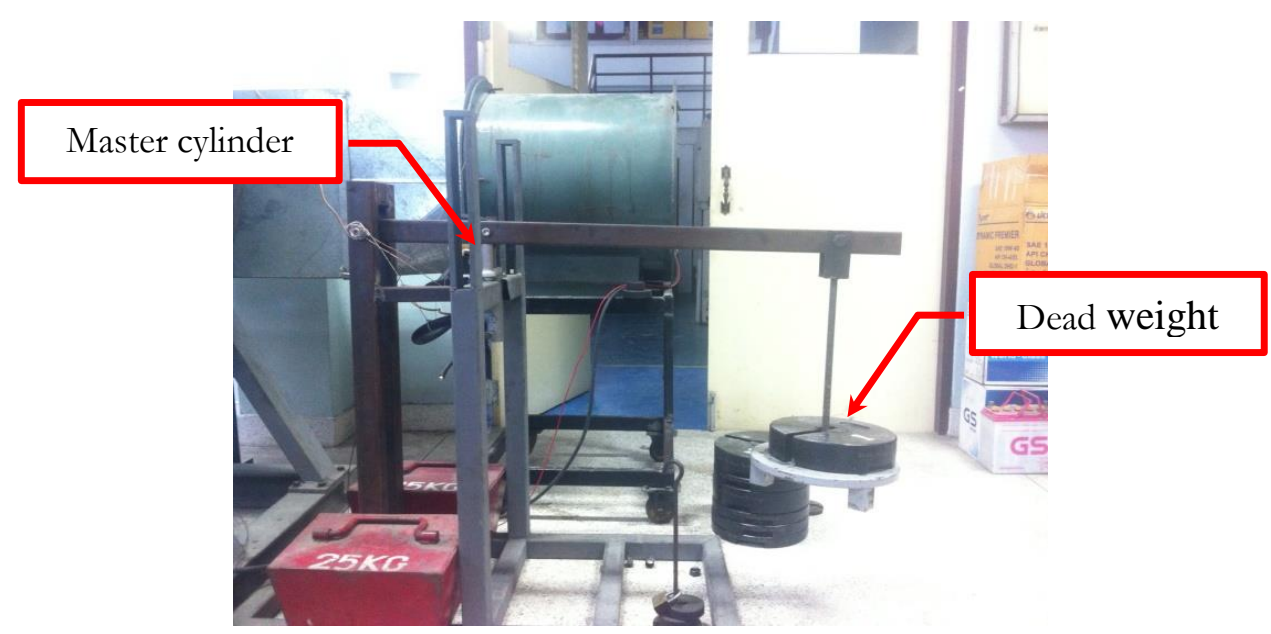

Fig. 5. Braking operation using the lump mass.

Table 2. Testing condition.

\begin{tabular}{|c|c|c|c|c|}
\hline $\begin{array}{l}\text { Pressure } \\
(\mathrm{MPa})\end{array}$ & $\begin{array}{c}\text { Temperature } \\
\left({ }^{\circ} \mathrm{C}\right)\end{array}$ & $\begin{array}{l}\text { Repetition } \\
\text { (no. of times) }\end{array}$ & $\begin{array}{l}\text { Initial braking } \\
\text { speed }(\mathrm{km} / \mathrm{h})\end{array}$ & $\begin{array}{c}\text { Wind speed } \\
(\mathrm{m} / \mathrm{s})\end{array}$ \\
\hline 2 & 100 & \multirow{3}{*}{ More than 3} & \multirow{3}{*}{50 and 80} & \multirow{3}{*}{11} \\
\hline 4 & 200 & & & \\
\hline 6 & 300 & & & \\
\hline
\end{tabular}

To determine the vibration value, experimental analysis was achieved using one degree of freedom (DOF) based testing (out-of-plane).There are five types of vibration for a brake system based on different frequencies as squeal, howl, groan, moan and judder [20]. For vibration, howl, groan, moan and judder are examples of phenomena. The vibration of brake system components during the braking action results in low frequencies $(<1 \mathrm{kHz})$. Therefore, a specific accelerometer which could measure vibration between 1 and $1 \mathrm{kHz}$ was installed on the brake caliper device to obtain vibration data as shown in Fig. 6. An equivalent force was generated from the amplitude and frequency during vibration by the brake system which was also capable of extreme temperature operation. For specific temperatures, measurement of two temperature points (brake pad and disc surface) was sufficient to control the braking system [21]. These experimental techniques relied on the temperature resulting from friction changes which was presumed to be related to the brake factor. For example, research on contact stiffness of the brake friction material related to stability was conducted by Lee et al. [22]. Day et al. [23] also described how the thermal effect of contact pressure on drum and disc expansion transferred through the process of thermoelastic instability. The set up for each specific temperature investigation is shown in Fig. 6. 


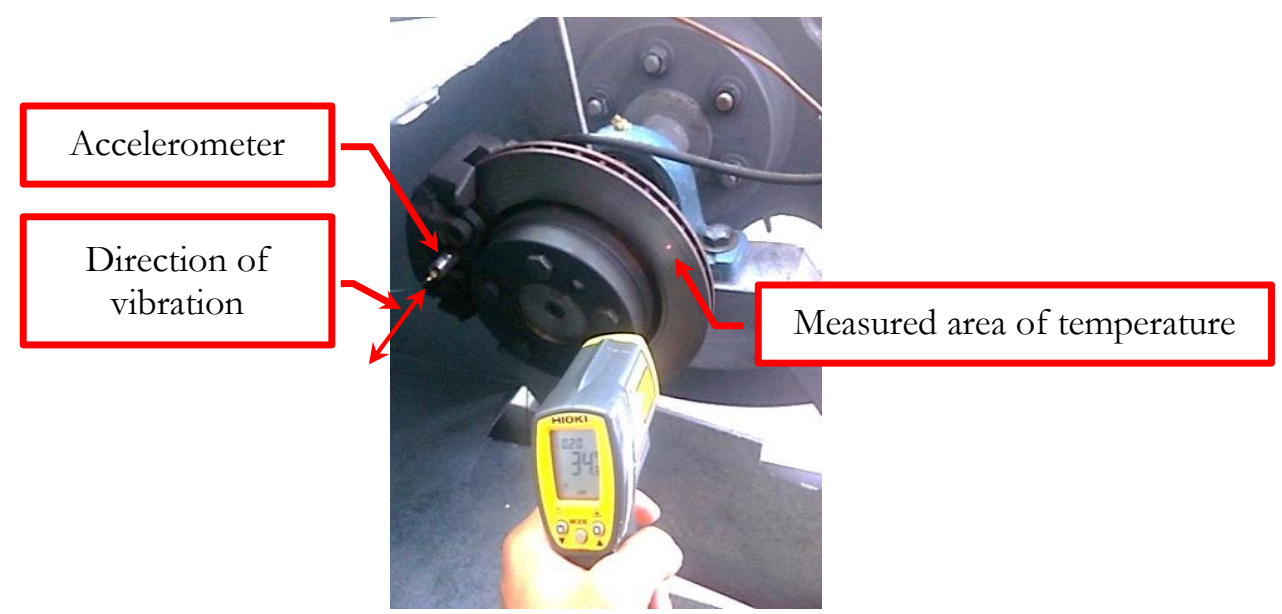

Fig. 6. Temperature investigation and accelerometer installation.

\section{Data Analysis and Results}

Following the research concept and methodology, data analysis and results were categorised into three sections as follows.

\subsection{Results of $100^{\circ} \mathrm{C}$ of Initial Braking Temperature}

For the sequence at $100^{\circ} \mathrm{C}$ of initial braking temperature, braking at $50 \mathrm{~km} / \mathrm{h}$ was investigated. A one-DOF accelerator was used as the engineering tool. Results showed that the highest vibration at a pressure of 4 MPa. The vibration amplitudes of the front vented brake disc (FV) and the back vented brake disc (BV) were 4.1 and $2.8 \mathrm{~m} / \mathrm{s}^{2}$ respectively, indicating that FV caused $31.7 \%$ more vibration than BV as shown in Fig. 7. On the other hand, testing at $2 \mathrm{MPa}$ hydraulic pressure gave the minimum vibration. The vibration amplitude of $\mathrm{FV}$ was $4.1 \mathrm{~m} / \mathrm{s}^{2}$, while BV recorded a reduction of $36.6 \%$ at $2.6 \mathrm{~m} / \mathrm{s}^{2}$.

For initial braking at $80 \mathrm{~km} / \mathrm{h}$, the result was similar to the previous test. The maximum acceleration at $4 \mathrm{MPa}$ pressure was 5.4 and $4.8 \mathrm{~m} / \mathrm{s}^{2}$ for FV and BV respectively, a difference of $11.1 \%$ as shown in Fig. 8 . However, this result indicated that the minimum acceleration occurred at $6 \mathrm{MPa}$ hydraulic pressure. The accelerations of FV and BV were 4.4 and $4.3 \mathrm{~m} / \mathrm{s}^{2}$ respectively, only a $2.3 \%$ difference. Thus, vibration of the brake disc showed maximum response at $50 \mathrm{~km} / \mathrm{h}$ of the initial braking condition and $4 \mathrm{MPa}$ hydraulic pressure. On the other hand, $6 \mathrm{MPa}$ hydraulic pressure was resonant at $80 \mathrm{~km} / \mathrm{h}$ initial braking condition.

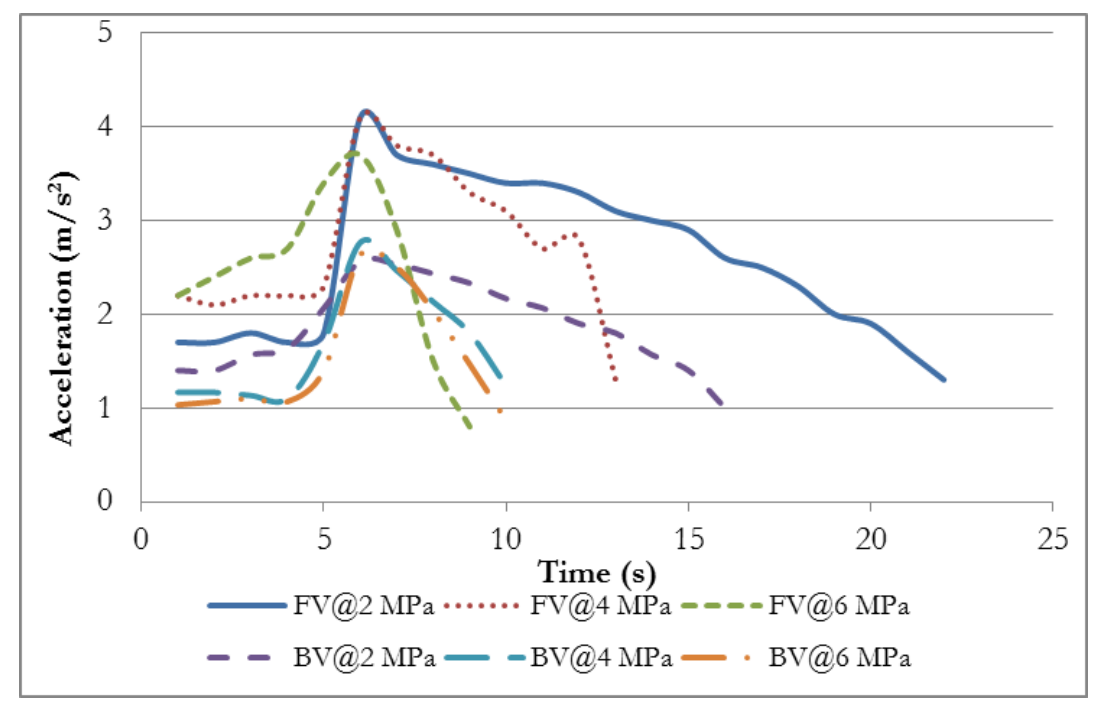

Fig. 7. Acceleration of both brake discs at $50 \mathrm{~km} / \mathrm{h}$ and $100^{\circ} \mathrm{C}$. 


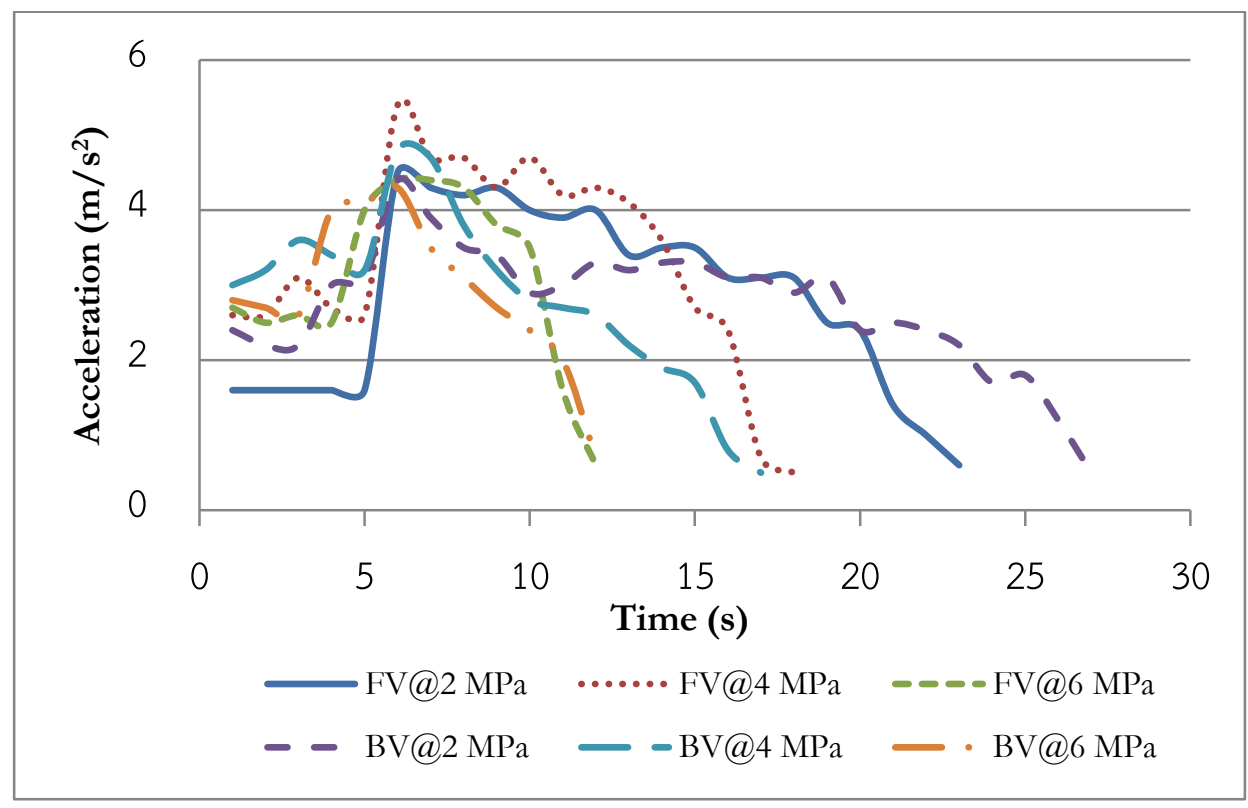

Fig. 8. Acceleration of both brake discs at $80 \mathrm{~km} / \mathrm{h}$ and $100^{\circ} \mathrm{C}$.

\subsection{Results of $200^{\circ} \mathrm{C}$ of Initial Braking Temperature}

For the sequence at $200^{\circ} \mathrm{C}$ of initial braking temperature, initial braking at $50 \mathrm{~km} / \mathrm{h}$ was tested. Results indicated that maximum vibration appeared at hydraulic pressure of $4 \mathrm{MPa}$. The amplitudes of oscillation of FV and BV were 4.6 and $2.6 \mathrm{~m} / \mathrm{s}^{2}$ respectively. Thus, FV caused $43.5 \%$ more vibration than $\mathrm{BV}$ as shown in Fig. 9. In contrast, a pressure of $2 \mathrm{MPa}$ gave the minimum vibration at 2.5 and $4.1 \mathrm{~m} / \mathrm{s}^{2}$ for FV and $\mathrm{BV}$ respectively with $39.1 \%$ difference. The slope of the vibration response at $200^{\circ} \mathrm{C}$ was lower than $100^{\circ} \mathrm{C}$ because of the temperature effect.

For initial braking at $80 \mathrm{~km} / \mathrm{h}$, the trend was similar to results at $50 \mathrm{~km} / \mathrm{h}$. Maximum acceleration appeared at $4 \mathrm{MPa}$ pressure with 4.5 and $4.4 \mathrm{~m} / \mathrm{s}^{2}$ for FV and BV respectively, a $2.2 \%$ difference as shown in Fig. 10. On the other hand, hydraulic pressure of $6 \mathrm{MPa}$ gave the minimum acceleration at 4.2 and 4.1 $\mathrm{m} / \mathrm{s}^{2}$ for FV and BV respectively, a 2.3\% difference. It was also evident that BV could stop more quickly at low speed conditions compared to FV. In contrast, FV decelerated well at high speed conditions compared to BV. 


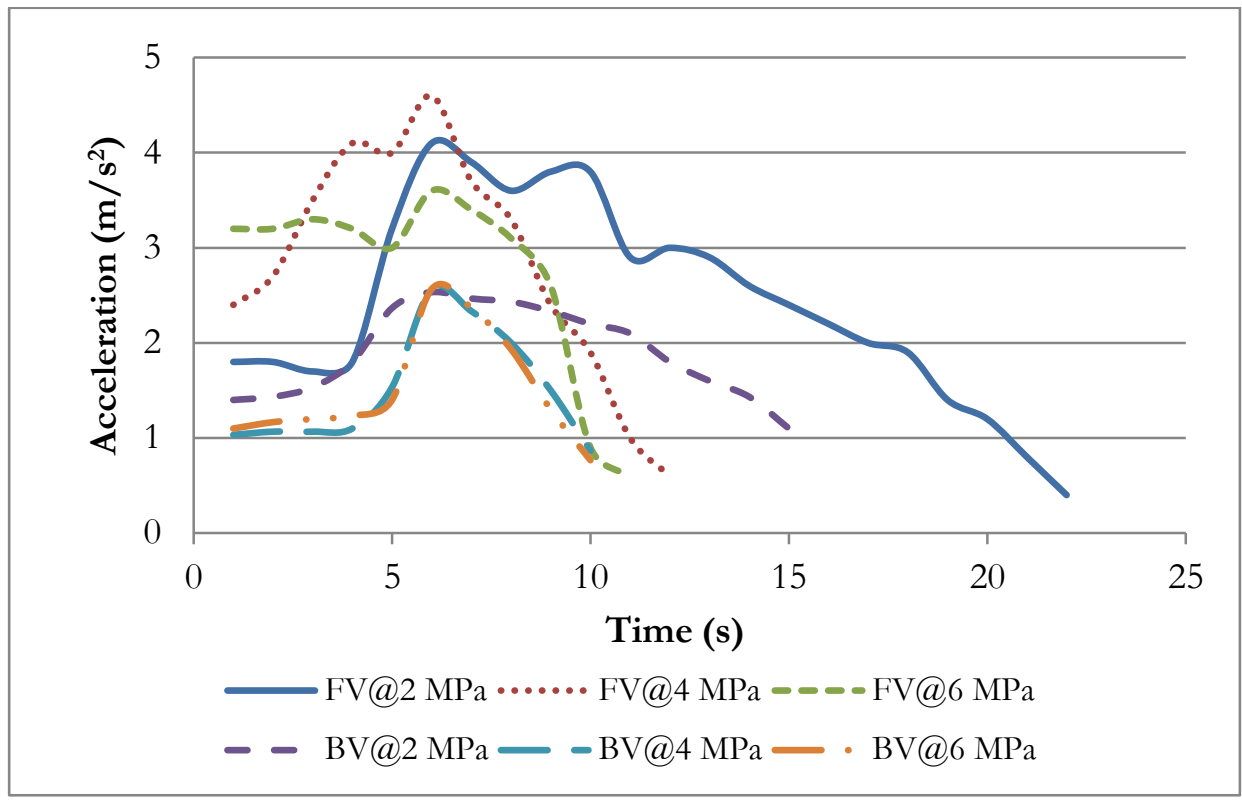

Fig. 9. Acceleration of both brake discs at $50 \mathrm{~km} / \mathrm{h}$ and $200^{\circ} \mathrm{C}$.

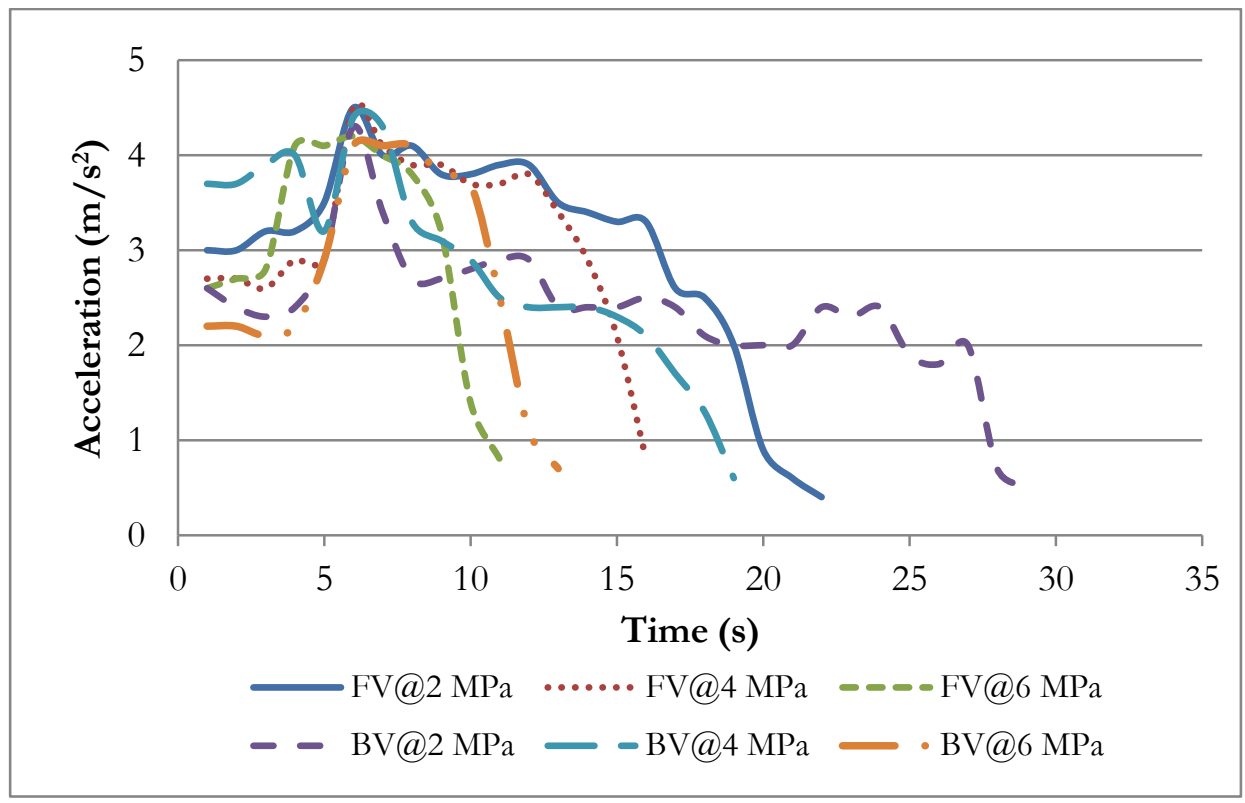

Fig. 10. Acceleration of both brake discs at $80 \mathrm{~km} / \mathrm{h}$ and $200^{\circ} \mathrm{C}$.

\subsection{Results of $300^{\circ} \mathrm{C}$ of Initial Braking Temperature}

For the sequence at $300^{\circ} \mathrm{C}$ of initial braking temperature, initial braking at $50 \mathrm{~km} / \mathrm{h}$ was tested. Results indicated that BV gave reduced vibration during braking compared to FV. Maximum vibration occurred at $4 \mathrm{MPa}$ and the vibration amplitudes of $\mathrm{FV}$ and $\mathrm{BV}$ were 3.7 and $2.4 \mathrm{~m} / \mathrm{s}^{2}$ respectively. FV gave $35.1 \%$ more vibration than BV as shown in Fig. 11. Likewise, hydraulic pressure of $6 \mathrm{MPa}$ produced the minimum vibration. Results showed the amplitude of vibration for $\mathrm{FV}$ at $3.5 \mathrm{~m} / \mathrm{s}^{2}, 31.4 \%$ higher than BV at $2.4 \mathrm{~m} / \mathrm{s}^{2}$.

At initial braking speed of $80 \mathrm{~km} / \mathrm{h}$, the maximum acceleration was at $4 \mathrm{MPa}$ pressure, with 5.1 and 4.3 $\mathrm{m} / \mathrm{s}^{2}$ for FV and BV respectively, a difference of $15.7 \%$ as shown in Fig. 12. Similarly, a hydraulic pressure of $6 \mathrm{MPa}$ gave minimum acceleration at 4.1 and $3.9 \mathrm{~m} / \mathrm{s}^{2}$ for FV and BV respectively, a $4.9 \%$ difference. Furthermore, decelerations at high speed for both FV and BV were similar compared to low speed conditions. 


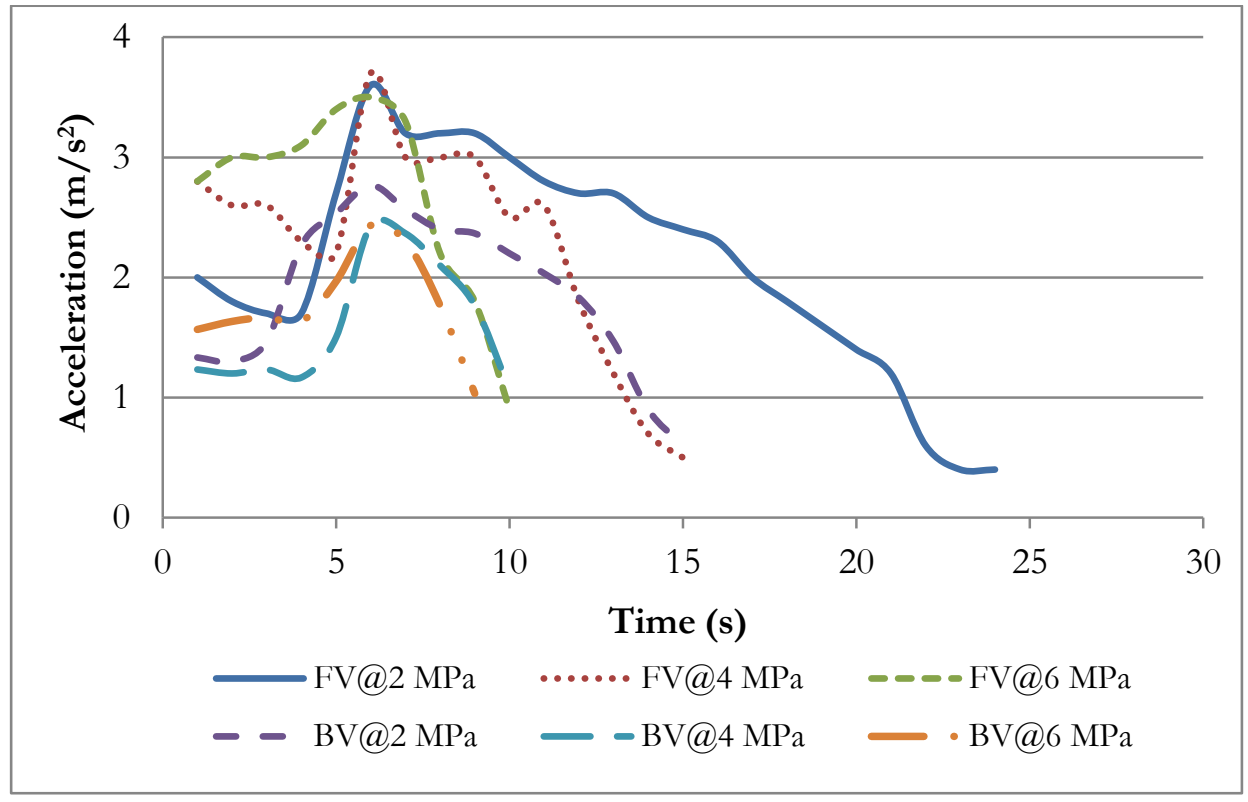

Fig. 11. Acceleration of both brake discs at $50 \mathrm{~km} / \mathrm{h}$ and $300^{\circ} \mathrm{C}$.

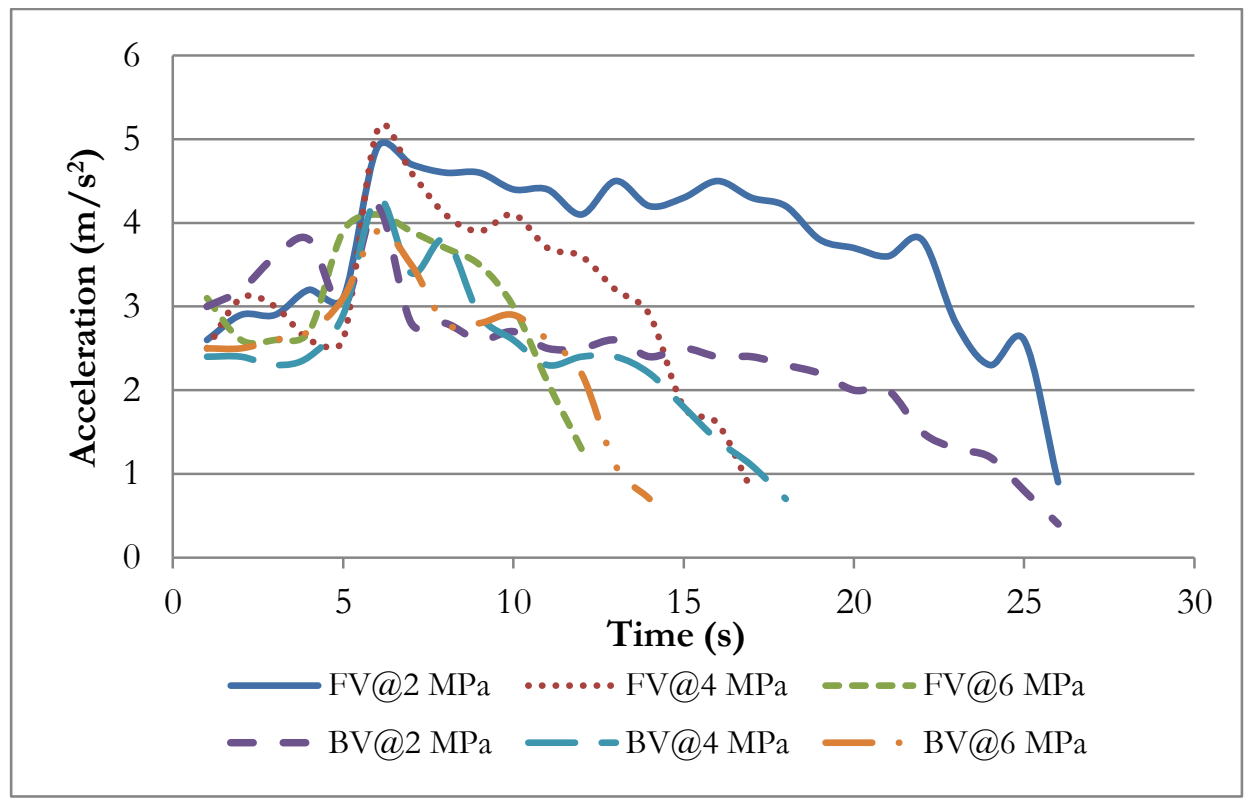

Fig. 12. Acceleration of both brake discs at $80 \mathrm{~km} / \mathrm{h}$ and $300^{\circ} \mathrm{C}$.

\section{Discussion and Conclusions}

This study of the heat transfer effect of both front and back vented brake discs related to vibration was conducted using a single dynamometer test bench following the JASO C406:2000 standard. Vibration results of both types of brake disc indicated that the back vented brake disc had less vibration than the front. An initial braking speed of $50 \mathrm{~km} / \mathrm{h}$ and hydraulic pressure of $2 \mathrm{MPa}$ gave $4.1 \mathrm{~m} / \mathrm{s}^{2}$ of vibration for the front vented brake disc, but only $2.6 \mathrm{~m} / \mathrm{s}^{2}$ for the back one, a difference of $36.6 \%$.

Furthermore, initial braking speed, hydraulic pressure and braking temperature were identified as important factors. Experimental results indicated that the braking vibration varied with the initial braking speeds. Hydraulic pressure at $4 \mathrm{MPa}$ showed maximum vibration compared to 2 and $6 \mathrm{MPa}$. Moreover, the 
results demonstrated that vibration of the front vented brake disc varied with braking temperature. However, the back vented brake disc alleviated the oscillation at high temperatures. For braking temperature of $200^{\circ} \mathrm{C}$ with initial braking speed at $50 \mathrm{~km} / \mathrm{h}$ and hydraulic pressure of $4 \mathrm{MPa}$, the difference between the vibrations of each type was $43.5 \%$.

The results agreed with research by Lakkam [16], who found that the front vented brake disc showed a larger temperature difference than the back with increased temperature dissipation. The front vented brake disc was therefore more likely to be subjected to potential stresses than the back disc. The front vented brake disc also showed a higher potential to deform during the operation than the back disc. A parametric study indicated that deformation was a dominant parameter for vibration response.

\section{Acknowledgement}

The authors are grateful for the financial support for this research from Rajamangala University of Technology Phra Nakhon.

\section{References}

[1] United Nations. (2014). E/ECE/324 and E/ECE/TRANS/505, Uniform Provisions Concerning the Approval of Vehicles of Categories $\mathrm{M}, \mathrm{N}$ and $\mathrm{O}$ with Regard to Braking. Available: http://www.unece. $\quad$ org/fileadmin/DAM/trans/main/wp29/wp29regs/updates/R013r8e.pdf [Accessed: July 13, 2015].

[2] US Department of Transportation. (2009). National Highway Traffic Safety Administration, 49 CRF Part 571 - RIN 2127-AK62, Federal Motor Vehicle Safety Standards; Air Brake Systems. Available: www. gpoaccess.gov/fr/index.html [Accessed: July 13, 2015].

[3] M. N. A. Hamid, C.-Y. Teoh, and Z. M. Ripin, "The operational deflection shapes and transient analysis of the brake shoes in drum brake squeal," Proc. Inst. Mech. Eng., Part D: J. Automobile Eng., vol. 227, no. 6, pp. 866-884, 2013.

[4] N. Millner and B. Parsons, "Effect of contact geometry and elastic deformations on the torque characteristics and a drum brake," Proc. Inst. Mech. Eng. Automobile Div., vol. 187, no. 26/73, pp. 317331, 1973.

[5] C. B. Winkler, "Predicting the braking performance of trucks and tractor-trailers," University of Michigan, Highway Safety Research Institute, 1976.

[6] T. D. Gillespie, P. S. Fancher, and L. K. Johnson, "An empirical model for the prediction of the torque output of commercial vehicle air brakes," University of Michigan, Highway Safety Research Institute, 1978.

[7] S. Saric, A. B. Hadiashar, and J. van der Walt, "Estimating clamp force for brake-by-wire systems: Thermal considerations," Mechatronics, vol. 19, pp. 886-895, 2009.

[8] P. Puangcharoenchai, S. Lakkam and S. Mongkonerdmanee, "An investigation on non-linear thermal conductivity behavior of brake pads," KMUTT Research and Development Journal, vol. 38, no. 3, pp. 243 253, 2015.

[9] K. Lee, "Numerical prediction of brake fluid temperature rise during braking and heat soaking," SAE Technical Paper, 1999-01-0483, pp. 1-9. 1999.

[10] P. Dufrénoy, G. Bodovillé, and G. Degallaix, "Damage mechanisms and thermomechanical loading of brake discs," European Structural Integrity Society, vol. 29, pp. 167-176, 2002.

[11] G. Cueva, A. Sinatora, W. L. Guesser, and A. P. Tschiptschin, "Wear resistance of cast irons used in brake disc rotors," Wear, vol. 255, pp. 1256-1260, 2003.

[12] J.E. Hunter, S. S. Cartier, D. J. Temple, and R. C. Mason, "Brake fluid vaporization as a contributing factor in motor vehicle collisions," SAE Technical Paper, 980371, pp. 277-296, 1998.

[13] F. Bagnoli, F. Dolce, and M. Bernabei, "Thermal fatigue cracks of fire fighting vehicles gray iron brake discs," Engineering Failure Analysis, vol. 16, pp. 152-163, 2009.

[14] F. Bergman, M. Eriksson, and S. Jacobson, "Influence of disc topography on generation of brake squeal," Wear, vol. 225-229, pp. 621-628, 1999.

[15] A. Papinniemia, C. S. Laia Joseph, J. Zhaob, and L. Loader, "Brake squeal: A literature review," Applied Acoustics, vol. 63, pp. 391-400, 2002. 
[16] S. Lakkam, K. Suwantaroj, P. Puangcharoenchai, S. Mongkonlerdmanee, and S. Koetniyom, "Study of heat transfer on front and back-vented brake discs," Songklanakarin J. Sci. Technol., vol. 35, no. 6, pp. 671-681, 2013.

[17] S. Lakkam and S. Koetniyom, "Optimization of constrained layer damping for strain energy minimization of vibrating pads," Songklanakarin J. Sci. Technol., vol. 34, no. 2, pp. 179-187, 2012.

[18] M. Triches, Jr., S. N. Y. Gerges, and R. Jordan, "Reduction of squeal noise from disc brake systems using constrained layer damping," Journal of the Brazilian Society of Mechanical Sciences and Engineering, vol. 26, 2004.

[19] J. Thevenet, M. Siroux, and B. Desmet, "Measurements of brake disc surface temperature and emissivity by two-color pyrometry," Applied Thermal Engineering, vol. 30, pp. 753-759, 2010.

[20] J. Wallaschek, K. H. Hach, U. Stolz, and P. Mody, "A survey of the present state of friction modelling in the analytical and numerical investigation of brake noise generation," in Proceedings of the ASME Vibration Conference, Las Vegas, 1999, pp. 12-15.

[21] H. S. Qi and A. J. Day, "Investigation of disc/pad interface temperatures in friction braking," Wear, vol. 262, pp. 505-513, 2007,

[22] S. M. Lee, M. W. Shin, W. K. Lee, and H. Jang, "The correlation between contact stiffness and stickslip of brake friction materials," Wear, vol. 302, pp. 1414-1420, 2013.

[23] A. J. Day, M. Tirovic, and T. P. Newcomb, "Thermal effects and pressure distributions in brakes," Proc. Inst. Mech. Eng., Part D: J. Automobile Eng. vol. 205, pp. 199-205, 1991. 